\title{
A Non-linear Model of the Trade Cycle: Mathematical Reflections on Hugh Hudson's Classic*
}

\author{
Ragupathy Venkatachalam, K. Vela Velupillai \& Stefano Zambelli ${ }^{\dagger}$
}

\footnotetext{
*Written in homage to Hudson?s by now 55 year-old classic in the Economic Record (Hudson, 1957), to which Velupillai was introduced by Goodwin, thirty years ago, the year he also first met Harcourt. It is also written in remembrance of the imminent 20th anniversary of Hugh Hudson?s untimely death, at the age of 62 , in 1993 . In passing, we would also like to remember that this is also the 50th anniversary of the establishment of the Australian Economic Papers, under the editorship of Hugh Hudson and assistant editorship by Geoff Harcourt, in 1962.

${ }^{\dagger}$ We are deeply indebted to our ASSRU Colleague, Selda Kao, for friendship, inspiration and intellectual help during the whole period this paper was being prepared. Velupillai, moreover, is particularly grateful to his old friend and mentor, Geoff Harcourt, for many years ? now bordering on forty - of encouragement for his enthusiasm for Hugh Hudson?s classic (ibid). Geoff and Velupillai share, apart from their passion for cricket, also Cambridge PhD supervision by Nicky Kaldor, mercifully only for one term. He 'escaped' and fell into the arms of Ron Henderson; Velupillai embraced, and was, in turn, embraced by, Richard Goodwin. But, in many ways, Kaldor is a key link between Harcourt, Hudson and Velupillai (and King's College, too) - but also Hicks and Goodwin, to both of whom he - Velupillai - has always been indebted for his lifelong commitment to endogenous nonlinear modeling of trade cycles (itself, by now, an old-fashioned phrase).
} 


\begin{abstract}
Hugh Hudson's classic article on A Model of the Trade Cycle has never, to the best of our knowledge, received the serious attention it deserved (and deserves, even now, 55 years after its original publication). It was written in what we would like to call the classic Hicks-Kaldor mode, i.e., relying on ingenious diagrammatic techniques for expository purposes, and, indeed, developing an innovative model of the trade cycle where interaction of monetary and real forces were modeled in terms of elements common to the classic nonlinear endogenous models of these two pioneers. In this paper we reconsider the analytical contents of Hudson's classic, and its expository technique, in the light of later, mathematical, approaches to the same topic. Our conclusion is that there is still much to be gained in the expository style adopted by Hudson; but, more importantly, there are innovative suggestion and still relevant suggestions on theorizing and understanding actual performances of advanced industrial economies. Above all Hudson's classic is permeated with the policy underpinnings of a rich model of the trade cycle.
\end{abstract}

JEL Codes: B41, E13, E32, E63

Keywords: Trade Cycles, Nonlinear Models, Endogenous Cycles, Monetary-Real Interactions, Generalised IS/LM Dynamics, 


\section{$\S 1$. By way of a Preamble}

"Hugh Hudson won the Stevenson Prize (for the best essay by a graduate student with less than six terms residence), edited Nicky's first two volumes of Collected Papers (Kaldor 1960a, 1960b), and was regarded by Richard Kahn and Joan Robinson as the brightest of us all (he had stiff competition from Amartya Sen, Lugi Pasinetti, Pierangelo Garegnani, John Whitaker, Charles Feinstein and Tom Asimakopoulos, for example)."

Harcourt, 2008, p. 147 ; italics in the original ${ }^{1}$

Non-linear, endogenous, theories of the trade cycle have been an integral part of macrodynamics - for brief periods even the dominant formalisms - for over sixty years. In their initial formalism, choosing Kaldor (1940) as a convenient starting point (although serious doctrine historical scholarship could easily push back the origins by at least a few decades, cf., Ragupathy \& Velupillai, 2012), they were conceptually motivated by Keynesian ideas and the analytical reasoning was entirely geometric.

However, after Richard Goodwin's formalization of an aggregate theory of the business cycle (Goodwin, 1951), in terms of generalized Keynesian concepts of the dynamic multiplier and the nonlinear accelerator, and Hicks (1950), this genre became almost invariably interpreted via, first, the mathematics of nonlinear differential equations and, later, formal dynamical systems theory (see Cartwright, 1952, 1964$)^{2}$. With the exception of the pedagogical and

\footnotetext{
${ }^{1}$ We wonder whether a brief and uncharacteristic memory lapse was the cause of the absence of the name of J. de V. Graff in this illustrious list! But no - Harcourt's memory remains as fresh as ever. By the time Velupillai came to King's as a research student, in the early 1970s, the legendary list of the 'best $\&$ the brightest' of that remarkable generation had been reduced (in the folklore of the times) to just three: de Graaff, Sen and Hudson. But the folklore of the early 1970s had forgotten that de Graff was at Cambridge one or two graduate student generations earlier than the 1954-1959 period to which Harcourt refers.

${ }^{2}$ Goodwin's formalisation, under the influence of Harrod (1936) and Phillip Le Corbeiller's mathematical guidance, aimed at 'reducing' Harrod's Keynesian Dynamics to a second-order nonlinear differential equation; Hicks, although also explicitly acknowledging Harrod's influence, was more directly inspired also by the Swedes and Robertson, so that his formalization was in terms of piecewise (linear) difference equations. It was the outstanding Japanese trio of Yasui, Ichimura and Morishima who began the identification of the economics of Kaldor (1940), Hicks (1950) and Goodwin (1951) via the mathematics of nonlinear planar dynamical systems (see Velupillai, 2008, Ragupathy \& Velupillai, 2012a).
} 
expository masterpiece on The Trade Cycle by Matthews $(1959)^{3}$, the subject never returned to its original non-mathematical, geometric, innocence - except in Hudson's classic $^{4}$.

This trend towards the mathematisation of cycle and growth theories, as indeed of macroeconomics in general, was part of the general movement in economics, with the lead taken by game theory, general equilibrium theory, welfare economics and microeconomics, already from the late 1920s and crystallised in the classics by von Neumann-Morgenstern, Samuelson, Nash and Arrow-Debreu.

It would be unthinkable to aim at a return to the pre-mathematical formalisms of the classical economists - not even to the crude mathematisations by the neo-classics - in general equilibrium theory of microeconomics (given that game theory seems to have come clothed in a mathematical framework, ab initio). Yet the aim of this paper, using Hudson's classic as a paradigmatic example of economic analysis in classic geometric mode, is to argue that mathematisation of nonlinear endogenous cycle theories did not add any new economic insights. Indeed, contrariwise, lulled economists into thinking that a deeper understanding of the existence, stability, uniqueness - the characteristic defining triptych of the mathematical maturity of an economics field (or so it seems!) - can only be provided by a particular kind of mathematical formalisation.

\footnotetext{
${ }^{3}$ Strangely with no references to Hudson (1957), despite the common 'Oxbridge' pedigree of the two works. Goodwin, in personal conversations with Velupillai, expressed displeasure, in his own inimitable sottovoce mode, at the 'rechristening' of the nonlinear accelerator as the capital stock adjustment principle in Matthews (ibid).

${ }^{4}$ The almost simultaneously appearing 'note' by Black (1956), also representing a Kaldor-Hicks story, could be said to represent this same 'non-mathematical, geometric, innocence'.
} 
Thus, in the next section we outline, concisely, the framework within which Hudson developed him classic model of the trade cycle. In section 3, Schinasi's development of a nonlinear, endogenous, mathematical theory of the trade cycle ${ }^{5}$, within the narrow framework of a particular kind of planar dynamical system, is used as a 'touchstone' to discuss the mathematical formalisation of Hudson's Model. We also try to show, in this section, that the economic underpinnings of Schinasi's nonlinear dynamics is entirely similar to that in Hudson's classic. In this section, we also argue that the particular mathematisation chosen by Schinasi is, in terms of the frontiers of research in dynamical systems theory, almost completely vacuous. Finally, therefore, in the concluding section, we wonder whether there are limits to mathematical formalisms that can be transcended by the method chosen by Hudson. To illustrate the possibility of this route of exposition and technique, we use a particularly felicitous example due to Goodwin.

We end with an endorsement of what we call Hudson's Precept for modeling capitalist economic dynamics - a precept that goes against both orthodoxy's acknowledged methodology and even that of Schumpeter's.

\section{\$2. Hudson's 'Classic' Model of the Trade Cycle}

"While we are on omissions, in [Laidler's] discussion of trade cycle theories he does not cite Nicholas Kaldor's 1940 paper, nor Hugh Hudson's 1957 follow-up using dynamic IS/LM analysis to model a cycle that arises from an integrated mixture of real and monetary factors." Harcourt, 2000, p.297; italics added.

Hudson stated, with unambiguous clarity, the purpose of his article:

“... to present a model of the trade cycle which emphasizes the interaction of real and monetary forces. The following pages consist of a synthesis of existing ideas .... . The main justification for this synthesis is that the suggested technique of analysis, with its explicit introduction of monetary forces, provides a useful expository device."

Hudson (op.cit, p. 378; italics added)

\footnotetext{
${ }^{5}$ By this time - i.e., 1981 - the old phrase 'trade cycle' had been replaced by 'business cycle'.
} 
We are convinced that Hudson succeeded admirably in providing 'a useful expository device'superior, in its 'expository' roles, to the rigidity of a formal, mathematical, exposition. But what was the 'technique of analysis', and where and how did - or does - it differ from an analysis based on mathematical techniques?

Hudson's 'technique of analysis' which he claims - and we concur - is 'a useful expository device' is a 'diagrammatic account of [a] dynamic model' (loc.cit, p.378), but is so only in the hands of someone who is a 'master' of his economics and makes the diagrams 'servant' ${ }^{6}$. In this he follows a noble Cambridge tradition, less of Marshall, than of Robinson (1933) of The Theory of Imperfect Competition and Goodwin, who made the geometry of dynamics an expository device of supreme fertility and elegance (to which we return in the final section).

Hudson's exemplary diagrammatic expositions do not use any advanced techniques or concepts economic, geometric or mathematical - than that which is available to any undergraduate student of economics (even if, as in current orthodox pedagogy, all Keynesian elements are eschewed). Thus, only six diagrams are derived - on the basis of absolutely elementary (even if flawed in the eyes of untrammeled optimizers and 'micro-foundationalists') and thoroughly plausible economic reasoning, completely faithful to gross observable behavior of aggregate economies, even as represented by national account data: the $I S, L M, I Y$ and $S Y$ 'schedules', with the hilfskonstruktion of the $I$ and $S$ schedules in the $r-I$ and $r-S$ planes, respectively ${ }^{7}$.

These diagrammatic devices enable Hudson to achieve the following:

a) 'To present a model of the trade cycle which emphasizes the interaction of real and monetary forces.' (loc.cit, p.378) - thereby circumventing the Hicksian mode of introducing the

\footnotetext{
${ }^{6}$ See, below, the observation by Harcourt at the beginning of the concluding section.

${ }^{7}$ All symbols have their usual, elementary, textbook interpretations.
} 
monetary factor 'as a deus ex machina, made necessary by the deficiencies of the real cycle' (ibid.).

b) To achieve the dynamics of an aggregative economy, with its monetary and real forces interacting to adjust towards an equilibrium - which may or may not be stable - at appreciably different rates, entirely justified by broad and observable empirical experiences. More specifically, the assumption is that 'monetary equilibrium [pace Myrdal!], and the adjustment of investment to the rate of interest are achieved instantaneously, while only the goods market takes time to adjust via the multiplier process.' (loc.cit., p. 381).

c) The equilibria are themselves characterized, in classic correspondence principle fashion, in terms of entirely plausible, if only qualitative, assumptions on the various partial responses of investment, consumption, money demand \& supply and savings, at the aggregate level, to variations in (monetary) interest rates, aggregate levels of activity and aggregate (monetary income $)^{8}$. Naturally, the puritan seeking intertemporally optimizing, microfounded, derivation of aggregate behavioural relations - notwithstanding the Sonnenschein-Debreu-Mantel results - will be less than satisfied with such 'cavalier' characterisations of equilibria.

d) Expectation revisions, determined by the 'growth of capital ... leading to a liquidity crisis' (pp. 384-5 - indeed, as experienced by most - if not all - contemporary economies), 'irreversibility of the IS schedule' due to expectations, determining 'the timing of the crisis and the commencement of the downswing' (p. 385) are most convincingly expressed in terms of Keynes's notion of '... a sudden collapse of the marginal efficiency of capital' Keynes, 1936, p. 315). Any discerning reader, even with only a cursory glance at the current economic malaise in the global economy, could not but agree with Hudson's perceptive reasoning (p.

\footnotetext{
${ }^{8}$ Symbolically represented, most conventionally, by terms such as $I_{y}, S_{y}, I_{r}, S_{r}, M_{y}, L_{y}, L_{r}, C_{y}$ and $C_{r}$, signifying, for formal algebraic purposes, partial derivatives of the upper-case variable with respect to the subscript variable.
} 
385), from the combination of 'expectation revisions' and the 'irreversibility of the $I S$ schedule', that 'the onset of the downswing and its subsequent speed are made more spectacular and catastrophic'.

e) Most ingeniously, Hudson also derives regime when the $I S$ schedule slopes downward for a considerable range of variations in the $r$ - $Y$ plane (see his Fig. 6, p. 388 and our Fig. 1, below). The policy implication of an economy in this regime is also of significant current relevance (p. 383): 'This may mean that a regime of cheap money many not be adequate, by itself, to produce full employment.'

f) Finally, lags (Lundbergian, Robertsonian; p378 \& 383), 'bunching of innovations' (in 'Schumpeterian' senses, p. 382), the fertile and imaginative use of the distinction between (Marshallian!) short- and long-period schedules ${ }^{9}$, all play their qualitative and plausible roles in the overall real-monetary dynamics derived and discussed, always with policy considerations in focus.

\section{§3. The Mathematical Formalisms of Hudson's Model}

"I would go through the algebra but, mainly, I used a simple diagram showing $\bar{I} / Y_{f}$ as autonomous and $S / Y_{f}$ as an increasing function of $\Pi / Y_{f}$, where $\bar{I}=$ (autonomous) investment, $\Pi$ = profits, $S=$ saving and $Y_{f}=$ long-period full employment income. (It was the late Hugh Hudson who suggested this diagram to me.)."

Harcourt, 2001, p. 98; italics added.

By 'the mathematical formalism of Hudson's model' we mean the unintended and unconscious mathematisation of a nonlinear, endogenous, theory of aggregate fluctuations, exploiting results peculiar to planar dynamical systems, which 'forced' the economics to

\footnotetext{
${ }^{9}$ Unlike the mathematically motivated practice of the dynamic macroeconomic theorist identifying the long-term with steady-state, equilibrium, values, obtained by 'solving' systems of differential, difference, or mixed difference-differential equations - without any indication of how, exactly, these 'solutions' are implemented, on any kind of computer (whether of the human or machine variety). This is only the other side of the usual practice of 'proving the existence of equilibria', in the general equilibrium tradition, without any consideration as to how such 'existence' can be constructed or computed.
} 
conform ('servant') to a mathematical framework ('master'), having started off with the rich, qualitatively economic, dynamic tapestry, diagrammatically described and discussed in the previous section.

Nonlinear endogenous mathematical theories of aggregate fluctuations can be identified in terms of three, more-or-less, non-overlapping periods of formalization, underpinned by, and dependent on, independent developments in nonlinear theories of differential, difference and mixed difference-differential equations systems. In terms of economic applications, they were, first of all, the period from about the late 1940s till about 1967; secondly, from about 1967 till about the early 1980s; and, thirdly, in the post-1980s era.

The first period can easily be identified with the works of the remarkable Japanese trio Yasui, Ichimura and Morishima (cf., Velupillai, 2008), who used the then easily available results proving the existence, uniqueness and stability of planar nonlinear differential equations to appropriately reformulated systems of equations developed by Kaldor, Goodwin and Hicks. The second period, which, in a way, can be characterized as the period when the Phillips-curve 'wisdom' supplemented the neo-classical synthesis of IS-LM macroeconomics - but, from the point of view of the mathematics of nonlinear differential equations, can be said to have originated in Rose (1967), and his introduction of the use of the PoincaréBendixson theorem ${ }^{10}$. The third period could be said to have been initiated with the series of important contributions by Richard Day (and his collaborators), from about the early $1980 \mathrm{~s}^{11}$

\footnotetext{
${ }^{10}$ Rose $(1966,1967,1969)$ and Chang \& Smyth (1971) may be said to have been the fountainhead of this tradition (cf., Ragupathy and Velupillai, 2012 for full details). It is surprising that,Rose, a pupil of Hicks (Velupillai is indebted to the late Bob Clower for this information), does not refer to Hudson in any of his three important papers of the late 1960s.

${ }^{11}$ Of course, the classic of this genre is Gale (1973), followed by Day \& Benhabib (1982) and the economic underpinnings were provided by OLG models and generalisations of a kind of $I S-L M$ model.
} 
The most directly relevant contribution to the issue at relevance here is Schinasi (1981), where, at the very outset, the author states, with admirable unambiguity, the method to be adopted in the paper (p. 649, italics added):

"The nonlinear dynamic approach to modeling cycles used either a variant of the Poincaré-Bendixson theorem, to prove the existence of closed orbits, or a theorem on Leinard's equation (sic!) ${ }^{12}$ (a second order non-linear differential equation) to prove the existence, uniqueness and stability of limit cycles.

This paper shows that the output dynamic of a modified version of a traditional, dynamic IS-LM macro-model is reducible to Leinard's equation. ... It is shown that for cases in which the general equilibrium of the model is locally unstable, the model is nevertheless globally stable in the sense that all locally unstable points converge to a unique and stable limit cycle."

We are not told of the economic significance of 'to prove' the existence, uniqueness and stability of limit cycles', whether using the Poincaré-Bendixson theorem or, after 'reducing' IS-LM dynamics to Liénard's equation, using the Levinson-Smith theorem (as in Schinasi's paper); nor are we informed that the Japanese trio of Yasui, Ichimura and Morishima had introduced the use of this theorem, more than thirty years earlier, for the Kaldor, Hicks \& Goodwin real systems.

Hudson proved nothing; nor, mercifully, did he emasculate his economics to 'serve' the 'master', the nonlinear dynamic approach to modeling cycles, 'to prove the existence of closed orbits', whether they were to be unique, stable - locally or globally - or even try to reduce his perfectly economically motivated algebra and geometry to any kind of 'second order non-linear differential equation'.

Yet, the diagram used by Schinasi (op.cit, p. 651, Figure 1) is:

\footnotetext{
${ }^{12}$ Surprisingly, in this paper by Schinasi, in which the Liénard equation is crucial, the name is systematically misspelled!
} 


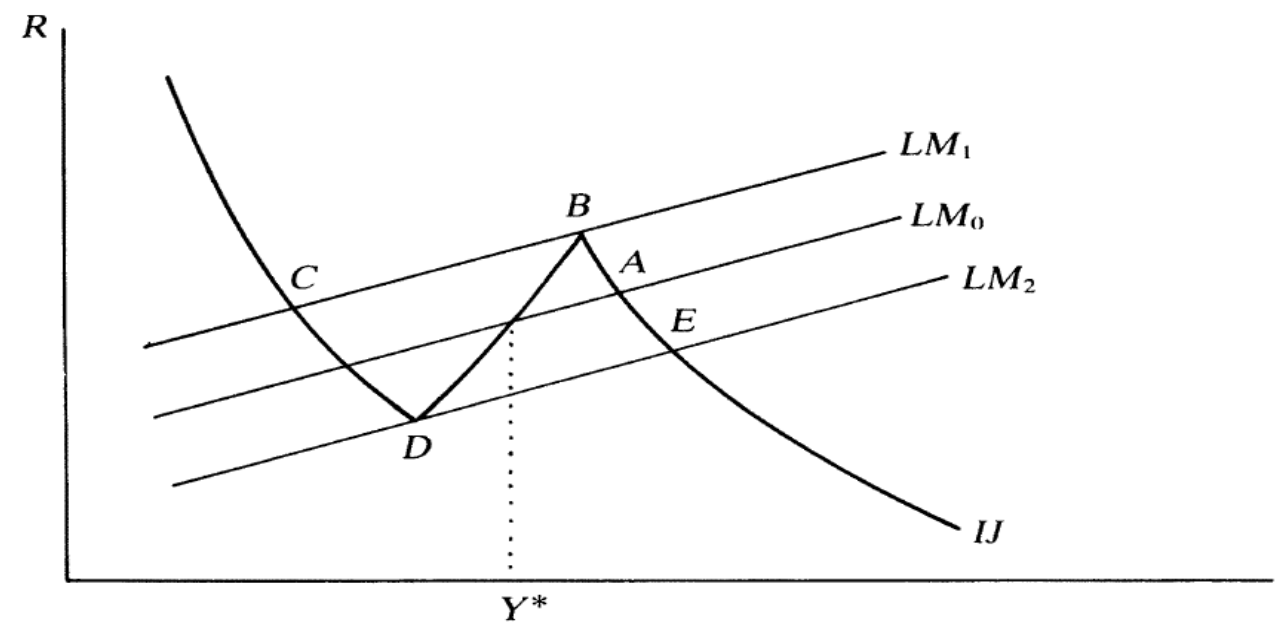

Figure 1

This is 'almost' exactly identical with, and derived also with 'almost' similar economic underpinnings in Hicks and Kaldor, by Hudson and shown as Figure 6 (ibid., p.388) ${ }^{13}$ :

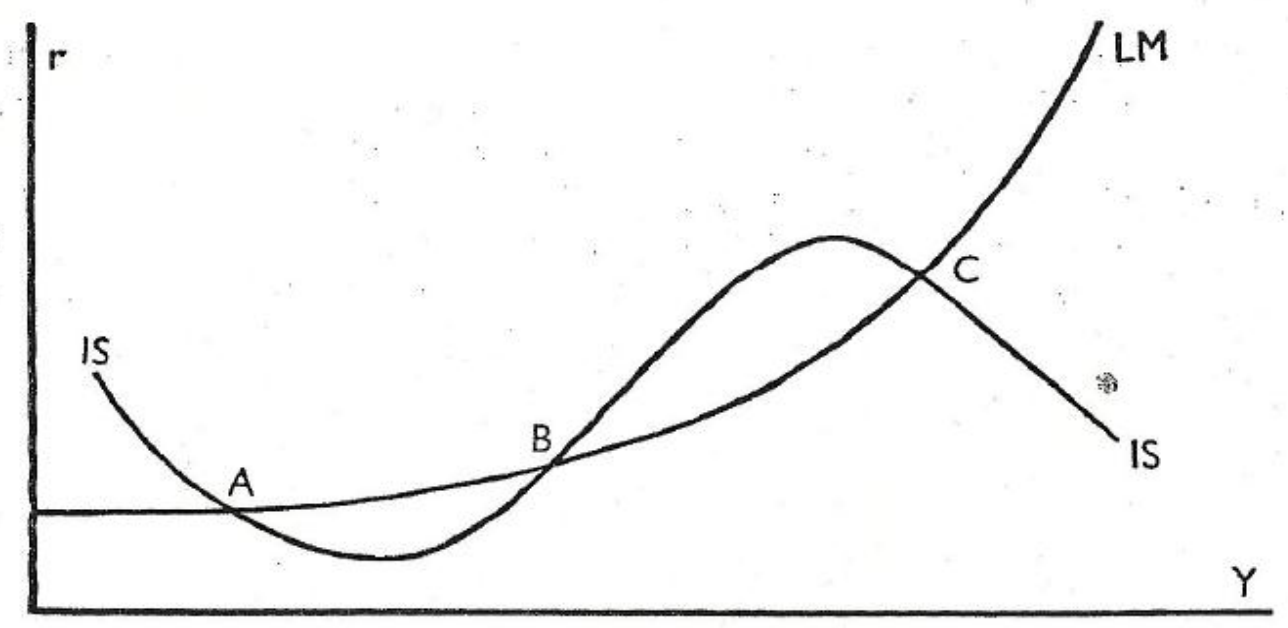

Figure 2

Hudson, using as a direct analogy Kaldor's method of going from Kalecki's $S$-shaped-curve ${ }^{14}$ for Investment decisions to his own highly ingenious $I-S$ dynamics in the $r-Y$ plane, generalized, in an imaginative way, the traditional $I S-L M$ interaction non-linearly as in Figure 2, above.

${ }^{13}$ The first 'almost' refers to the fact that the non-smooth turning points in Schinasi's diagram are inappropriate for the mathematics he uses; whereas, Hudson's figures are impeccably 'faithful' to the economics he invokes.

${ }^{14}$ See Kalecki's discussion of the derivation and use of his $\phi$-curve in (Kalecki, 1937, p. 87, ff.) and Kaldor (1940), Appendix, p. 89, ff. 
Now, what, and how, does the invoking of the Poincaré-Bendixson or the Levinson-Smith theorems to prove anything contribute to the economics - theoretically or practically (i.e., empirically or from a policy-oriented point of view - which Hudson's paper bristles with) of a theory of the trade cycle?

We shall answer this question for the Poincaré-Bendixson theorem, only because it is more widely invoked in 'proving' the existence of a stable limit cycle, often with uniqueness even in current research. However, almost all the (negative) remarks in the following discussion, referring to the Poincaré-Bendixson theorem, applies pari passu to the LevinsonSmith theorem.

First of all, the Poincaré-Bendixson theorem is valid only for planar dynamical systems; there is no generalization to higher dimensions. Nothing in Hudson's economic analysis need be constrained to 2-dimensional diagrams; ingenious extensions - say with the help of Richard Goodwin's geometric finesse and expertise - to three (and even higher!) dimensional diagrammatic analysis is entirely feasible, on the basis of the economics that underpinned the 2-dimensional diagrams.

Secondly, the proof of the Poincaré-Bendixson theorem invokes, at a crucial stage (see, Sternberg, 2010, § 10.6), the Jordan Curve theorem. Verifying the validity, in an empirical sense, of the Poincaré-Bendixson theorem requires checking for the satisfiability of the Jordan Curve theorem, which is constructively and computationally almost infeasible ${ }^{15}$.

\footnotetext{
${ }^{15}$ See Hales (2007). The Jordan curve theorem, using Higher-Order-Logic requires, for its computerized proof, c.a., 20 million 'logical' inferences: 138 definitions, 1381 lemmas and 'over 49,000 proof steps spread over 59,000 lines of computer code!
} 
Practically none of the formal results in Schinasi (op.cit) - or, indeed, in any similar mathematical contribution to nonlinear, endogenous, planar economic dynamics - can be validated by means of feasible computations.

Thirdly, on the other hand, every assertion and claim in Hudson, whether diagrammatically expressed or not, can be empirically verified, especially when stated in a qualitative mode (i.e., with 'signs', for example for the 'small' variations of variables with respect to changes in other variables of the model).

Finally, everything we have pointed out above regarding the Poincaré-Bendixson theorem applies not only to the Levinson-Smith theorem, but also to all those attempts that have been made to work with higher-dimensional generalisations of $I S$-LM dynamics, using bifurcation theories or so-called chaos theoretic tools (cf., again, Ragupathy \& Velupillai, 2012a).

\section{\$4. Limits of the Mathematical Formalism}

"This [the vexed question of mathematics]is a red herring. My own stance was influenced by Keynes. He argued that in a subject like economics there is a spectrum of appropriate languages, running from intuition and poetry through lawyer-like arguments to formal logic and mathematics. All have a role, depending upon the issue (or the aspects of an issue) being discussed. Mathematics is a good servant but a bad master, that is to say, always pose the economics of issue first, then see whether some form of mathematics may be of use in solving the problems thrown up."

Harcourt, 2003, p. 70; italics added.

How, then, can we make mathematics the 'servant' of the 'master' that is economic dynamics, in this case? We can do no better than to try to answer this question, maintaining fidelity to Hudson's chosen 'expository technique' of 'diagrammatic analysis', using a relatively unknown example devised and executed by Richard Goodwin, geometer in the classic Coxeter class ${ }^{16}$.

\footnotetext{
${ }^{16}$ Incidentally, one of the most elegant - yet also as neglected as Hudson's classic - Keynesian exposition, and also one of the earliest, Mabel Timlin's Keynesian Economics (Timlin, 1942) was richly, elegantly and appropriately illustrated with diagrams of unparalleled precision by H.S.M. Coxeter - easily the pre-eminent geometer of the $20^{\text {th }}$ century.
} 
Although a case can be made that Goodwin set out with the same aim as (much later) that which motivated researchers like Schinasi, once he had achieved it he reverted to traditional 'diagrammatic analysis'. He set out to show that 'the output dynamic of a modified version of a 'traditional', dynamic multiplier-nonlinear accelerator Keynesian macro-model is reducible to the Rayleigh-van der Pol equation' (with y signifying, as usual, real output):

$$
d^{2} y / d t^{2}+\chi(d y / d t) d y / d t+y=0
$$

$\chi(d y / d t)$ : is called the characteristic and is an auxiliary geometric device utilized to construct the dynamics of the above planar differential equation. It is called a cubic characteristic, in the particular case of the equation used by Goodwin (1951) - and all three of the Japanese pioneers, mentioned earlier - because, geometrically it looks as follows:

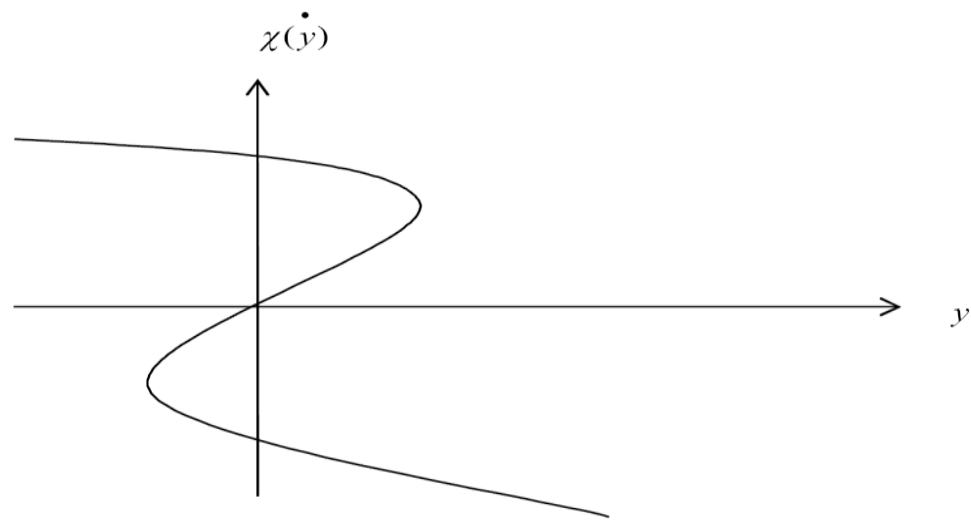

Figure 3

However, in reviewing the Hicks classic (Hicks, 1950), Goodwin realized, for purely economic reasons, two important caveats: one, that either the Hicksian 'ceiling' or his 'floor' were sufficient for the generation of an endogenous cycle in output; two, that the accelerator was 'dead' in the downturn phase of the cycle (also observed by Hudson). Geometrically, the two turning points in the above figure of the 'cubic characteristic' encapsulated the 'ceiling' and the 'floor'. However, the applied mathematics of planar, nonlinear dynamical systems, at that time did not allow for a 'characteristic' with only one turning point! 
Goodwin, harnessing all his powers of geometric reasoning constructed, by trial and error, a noncubic characteristic of the following form:

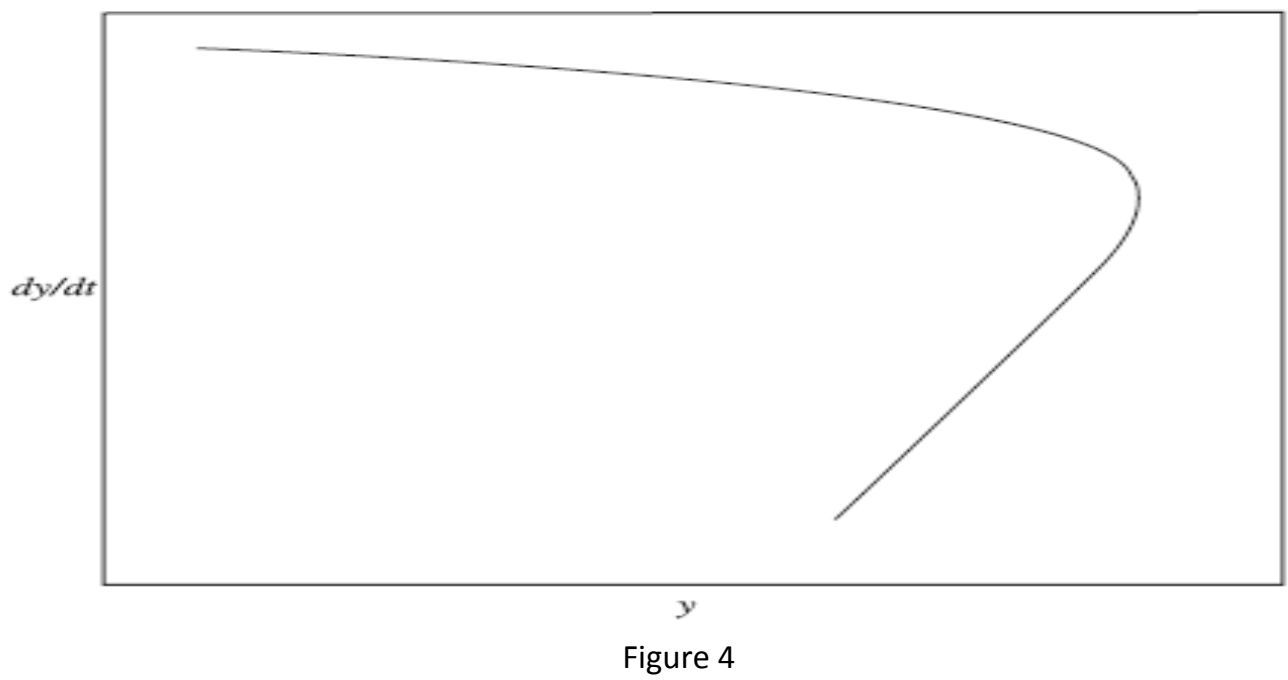

For which it was shown, a decade or so later, that the corresponding limit cycle was:

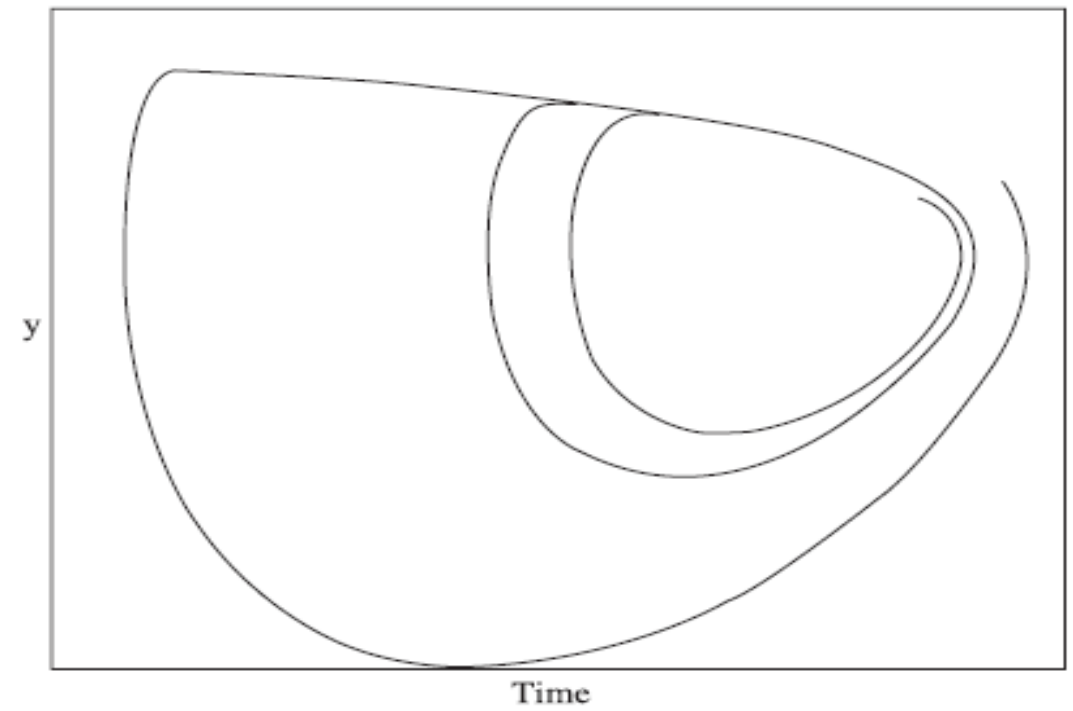

Figure 5

The point we wish to make are four:

a. First of all, the geometry was inspired by purely economic reasoning - the sufficiency of the 'ceiling' or the 'floor' for the generation of an endogenous, stable, cycle, on the plane.

b. No emasculation of any economic hypothesis was necessary to derive such a geometry. 
c. The particular characteristic had been considered infeasible for the construction of a limit cycle on the plane.

d. Existence and stability of the limit cycle were demonstrated by construction, maintaining every economic assumption of the model.

Sadly, the 'diagrammatic technique', even for 'expository purposes', seems to have been 'hollowed out' in the age of the digital computer. Those who appeal to the complex geometry generated and displayed on computer screens, as a result of simulations of analytically complex dynamical systems, even of low dimensions, forget that they fall foul of the mathematics of the computer - i.e., computability theory - when working on the interface between actual economic data and the data-types of the digital computer.

But this is quite another story, to which we have dedicated considerable study and research in recent times (cf., Velupillai, 2012).

Finally, there is the refreshing, completely original, underlying modeling philosophy that was the driving force underpinning Hudson's framework: '.. the view that growth should be regarded as a product of the cycle' (ibid, p. 389). We may call this Hudson's Precept, and contrast it with the dominant orthodoxy's modeling philosophy underlying cycle theory - i.e.,

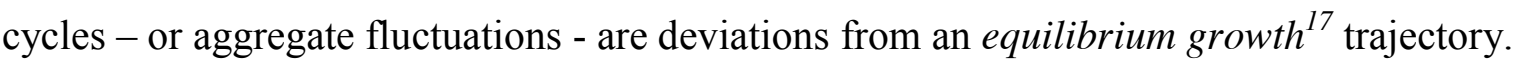

\footnotetext{
${ }^{17}$ We cannot resist quoting Hudson's acid view of 'equilibrium growth rates', buttressed by support from Paul Baran's review of Rostow's classic on 'stages of growth' (ibid, p. 389):

"Certainly, its [i.e., equilibrium rate of growth's] use to help provide a theoretical explanation of the economic growth of a capitalist system (where the government plays a passive role), only causes confusion, and leaves economists open to the charge that they ' ... explain with much pomp and circumstance a nation's economic growth by that nation's propensity to grow."
} 
Hudson's Precept can also be contrasted with Schumpeter's vision: that 'the cycle is simply the form that growth takes' (cf., for example Goodwin, 1990, p. 70).

We endorse, wholeheartedly, Hudson's utterly refreshing, completely unorthodox methodological - indeed, even, epistemological - vision, in the true Shumpeterian sense of the word (ibid, p. 389; italics added):

"Our conclusion is that a theory of the economic growth of a capitalist system must be the product of a detailed study of the cycles which produce this growth. Until economic growth can be integrated into models of the cycle in this way, cycle models are best derived independently of the question of growth."

\section{References}

Black, J (1956), A Note on Mr. Kaldor's Trade Cycle Model, Oxford Economic Papers, New Series, Vol. 8, \#. 2, June, pp. 151-163.

Cartwright, Mary (1952), Non-Linear Vibrations: A Chapter in Mathematical History, The Mathematical Gazette, Vol. XXXVI, \#. 316, May, pp. 81-88.

Cartwright, Mary (1964), From Non-Linear Oscillations to Topological Dynamics, Journal of the London Mathematical Society, Vol. 39, pp. 193-201.

Chang, W. W \& D.J. Smyth (1971), The Existence and Persistence of Cycles in a Non-Linear Model: Kaldor's 1940 Model Re-examined, Review of Economic Studies, Vol. 38, \# 1, January, pp. 37-46.

Day, Richard. H \& Jess Benhabib (1982), A Characterization of Erratic Dynamics in the Overlapping Generations Model, Journal of Economic Dynamics and Control, Vol.4, pp. 37-55.

Gale, David (1973), Pure Exchange Equilibrium of Dynamic Economic Models, Journal of Economic Theory, Vol.6, pp.12-36.

Goodwin, Richard. M (1950), A Non-Linear Theory of the Cycle, The Review of Economics and Statistics, Vol. XXXII, No. 4, November, pp. 316-320.

Goodwin, Richard. M (1951), The Nonlinear Accelerator and the Persistence of Business Cycles, Econometrica, Vol. 19, No.1, January, pp. 1-17.

Goodwin, Richard.M (1990), Schumpeter, Keynes and the Theory of Economic Evolution, Economia e Banca - Annali Scientifici, Vol. 3, pp. 69-94.

Harcourt, G. C (2000), Review of, Fabricating the Keynesian Revolution: Studies of the InterWar Literature on Money, the Cycle and Unemployment by David Laidler, Economica, New Series, Vol. 67, \#. 266, May, pp. 297-298. 
Hacourt, G. C (2001), 40 Years Teaching Post Keynesian Themes in Adelaide and Cambridge, History of Economics Review, Vol. 34, Summer, pp. 95-109.

Harcourt, G. C (2003), A Good Servant but a Bad Master, pp. 70-1, in: The Crisis in Economics: The Post-Autistic Economics Movement - the First 600 Days, edited by Edward Fullbrook, Routledge, London.

Harcourt, G. C (2006), Australians in Cambridge in the 1950s: A Comment on William Coleman's Conversation with Murray Kemp, History of Economics Review, Vol.43, Winter, pp. 146-149.

Hales, Thomas, C (2007), The Jordan Curve Theorem, Formally and Informally, American Mathematical Monthly, Vol. 114, December, pp. 882-894.

Harrod, Roy. F (1936), The Trade Cycle: An Essay, Clarendon Press, Oxford.

Hicks, John. R (1950), A Contribution to the Theory of the Trade Cycle, Clarendon Press, Oxford.

Hudson, Hugh. R (1957), A Model of the Trade Cycle, Economic Record, Vol. XXXIII, No. 66, December, pp. 378-389.

Kaldor, Nicholas (1940), A Model of the Trade Cycle, The Economic Journal, Vol. 50, March, pp. 78-92.

Kaldor, Nicholas (1960a), Essays on Economic Stability and Growth, Gerald Duckworth \& Co. Ltd., London.

Kaldor, Nicholas (1960b), Essays on Value and Distribution, Gerald Duckworth \& Co. Ltd., London.

Kalecki, Mihat (1937), A Theory of the Business Cycle, The Review of Economic Studies, Vol. 4, \#. 2, Feb., pp. 77-97.

Keynes, John Maynard (1936), The General Theory of Employment, Interest and Money, Macmillan and Co., Limited, London.

Matthews, R.C.O (1959), The Trade Cycle, Cambridge University Press, Cambridge.

Ragupathy, V \& K. Vela Velupillai (2012), Origins and Early Developments of the Nonlinear Endogenous Mathematical Theory of the Business Cycle, Economia Politica, Vol. XXIX, \#. 1, April, pp. 45-79.

Ragupathy, V \& K. Vela Velupillai (2012a), Existence proofs in nonlinear endogenous theories of the business cycle on the plane - the origins, ASSRU Discussion Paper Series, 10 -2012/1, Trento.

Robinson, Joan (1933), The Economics of Imperfect Competition, Macmillan And Co., Limited, London. 
Rose, Hugh (1966), Unemployment in a Theory of Growth, International Economic Review, Vol.7, No.3, September, pp. 260-282.

Rose, Hugh (1967), On the Non-Linear Theory of the Employment Cycle, Review of Economic Studies, Vol. 34, pp. 153-173.

Rose, Hugh (1969), Real and Monetary Factors in the Business Cycle, Journal of Money, Credit and Banking, Vol. 1, No.2, May, pp. 138-152.

Schinasi, Garry. J (1981), A Nonlinear Dynamic Model of Short Run Fluctuations, The Review of Economic Studies, Vol. 48, No.4, October, pp. 649-656.

Sternberg, Shlomo (2010), Dynamical Systems, Dover Publications, Mineola, New York. Timlin, Mabel (1942), Keynesian Economics, The University of Toronto Press, Toronto.

Velupillai, K. Vela (2008), Japanese Contributions to Nonlinear Cycle Theory in the 1950s, Japanese Economic Review, Vol. 59, \#. 1, March, pp. 54-74.

Velupillai, K. Vela (2012), Turing's Economics, Forthcoming in: Economia Politica. 